\title{
Dynamic Analysis of a Boost Topology with Ripple Cancellation and Comparison with the Conventional Boost
}

\author{
D. Díaz, D. Meneses, J.A. Oliver, O. García, P. Alou, J.A. Cobos \\ Universidad Politécnica de Madrid \\ Centro de Electrónica Industrial (CEI) \\ C/ José Gutiérrez Abascal, 2 \\ 28006 Madrid. SPAIN \\ Phone: + 34914117517 \\ e-mail: cei@upm.es
}

\begin{abstract}
The boost topology with ripple cancellation network allows input and output current ripple attenuation, which means the suppression of the input filter and a high reduction of the output filter. However, to achieve the ripple cancellation, the complexity and the number of components of the converter increase compared with the conventional boost. A detailed analysis has been developed to specify the advantages and drawbacks of this topology. This paper presents the averaged model that derives the complex transfer function of the topology. The theoretical transfer function has been obtained. Due to the complexity of the seventh order transfer function obtained, a simplified second order transfer function has been calculated in order to simplify control design calculations. A comparison between the analyzed topology and a conventional boost in terms of weight and losses has been carried out. To estimate input and output current ripple calculation, it is proposed the use of the ripple theorem, which allows an estimation of the efficiency of the cancellation network using the averaged model. A prototype to validate ripple cancellation and the dynamic analysis has been developed. Measured waveforms and bode plots are enclosed. Current ripple cancellation at the input and at the output on both conduction modes of the converter has been validated.
\end{abstract}

\section{INTRODUCTION}

In the design of a converter for a space application, weight, volume and efficiency become critic design parameters. A necessary element for the correct operation of the system is the filter, both at the input and at the output. Those two elements have a significant impact in the weight and size of the converter.

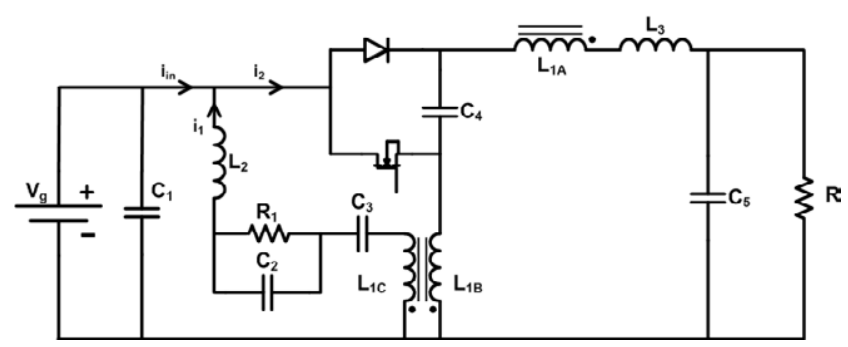

Figure 1. Schematic of the Boost Topology with Ripple Cancellation Network.
In [1], a new boost derived topology, a coupled inductor boost with ripple cancellation network was proposed (Figure 1). This topology shows a DC gain like the conventional boost converter. By an additional inductor, $\mathrm{L}_{3}$ (Figure 1), this topology also reduces the output current ripple. Further details about the basic operation of the topology and formulas relating inductances L1A and L2 to achieve input ripple cancellation can be found in [1].

Despite the increase in the number of components and also in the complexity of this topology, it has several advantages over the conventional boost converter, like the reduction or suppression of the input filter and the reduction of the output filter. An important issue of the ripple cancellation of this topology is that it is valid for any working condition, both on DCM and CCM and for all duty cycles. Those characteristics motivate further analysis, modeling and prototyping to evaluate more accurately the theoretical advantages of the topology, and also a comparison with the conventional boost converter.

In this paper, the averaged model of the boost converter with ripple cancellation has been obtained. The complex seventh order transfer function has been calculated and a second order simplification is presented. A comparison of the boost converter with ripple cancellation and the conventional boost in terms of dynamic behavior, weight and losses has been carried out. The averaged model is used to estimate the input ripple on both converters. Measurements of input and output current ripple cancellation and bode plots are shown.

\section{DYNAMIC CHARACTERIZATION OF THE BOOST TOPOLOGY WITH RIPPLE CANCELLATION NETWORK}

The analyzed topology is derived from the two inductor boost with coupled windings by adding the current cancellation network. It is known that, under certain circumstances, some boost derived topologies with coupled inductors [2] [3] can cancel the RHP zero, inherent to the classical boost converter. So, in order to evaluate RHP zero cancellation on the studied topology, the averaged model and the theoretical transfer function have been calculated. 
The averaged model [4] of the boost topology with ripple cancellation has been obtained (Figure 2) replacing the three windings transformer with the magnetizing inductance $\left(\mathrm{L}_{1 \mathrm{~A}}\right)$, and dependent voltage and current sources. Switching devices, MOSFET and diode, have been modeled with dependent voltage and current sources respectively. The design parameters $n_{A}, n_{B}$ and $n_{C}$ on Figure 2 are the number of turns of $\mathrm{L}_{1 \mathrm{~A}}, \mathrm{~L}_{1 \mathrm{~B}}$ and $\mathrm{L}_{1 \mathrm{C}}$ respectively.

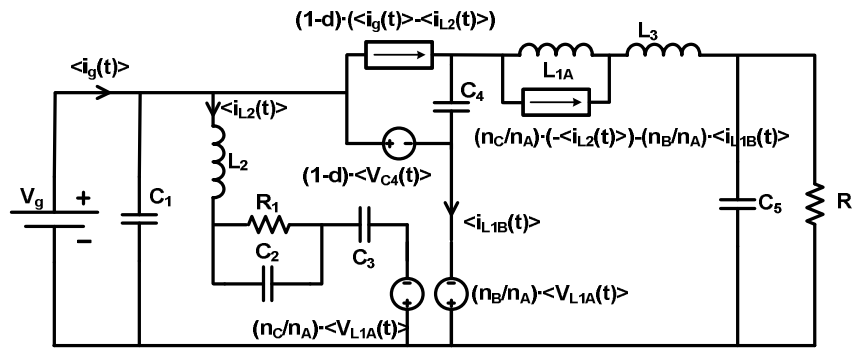

Figure 2. Averaged Model of the Boost Topology with Ripple Cancellation Network.

The validation of the averaged model has been carried out comparing the transient response of the averaged and the switched model at a duty cycle step (Figure 3).

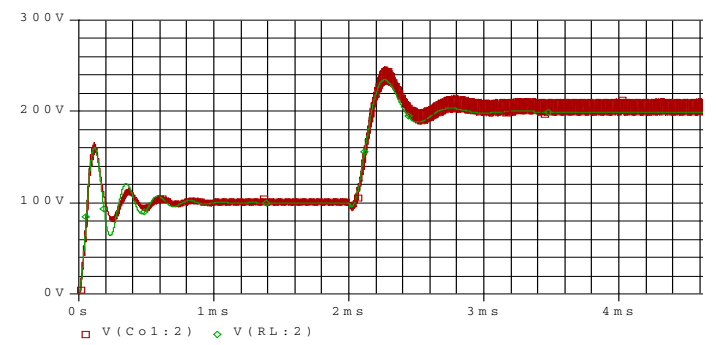

Figure 3. Averaged model validation by transient response of output voltage to duty cycle step.

An additional comparison has been done between the simulated bode plot and the measured transfer function. This comparison is shown on Figure 11 in section IV.

The next step is to analyze the bode plots of duty cycle to output voltage (Figure 4). There are two poles and a right halfplane (RHP) zero at low frequencies, and additional poles and zeroes at higher frequency but without influence on the control design calculations.

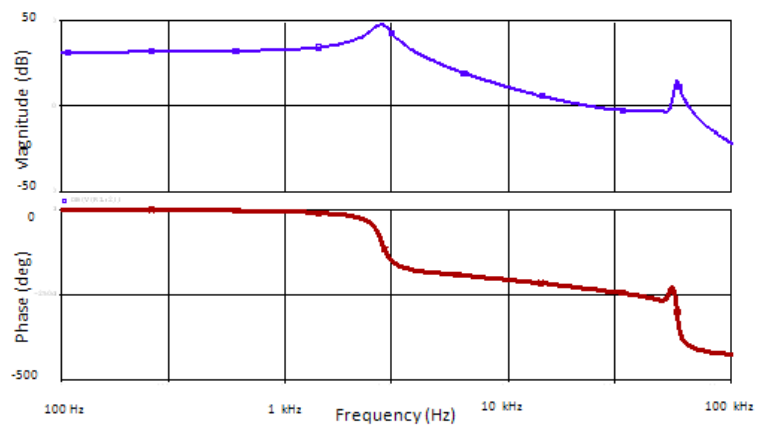

Figure 4. Simulated duty cycle to output voltage Bode plot.
The duty cycle to output voltage transfer function obtained is a complex seventh order system, with a fourth grade numerator and a seventh grade denominator. On Figure 5 are shown the averaged matrices of the state-space model of the topology [5], [6].

Because of the aim of the dynamic characterization is to evaluate the operating conditions that can produce the RHP zero cancellation, a simplified transfer function, based on the decoupling of the fast and slow subsystems method [7] [8], has been obtained. This new transfer function allows to develop an analytical study of the conditions that could entail a RHP zero cancellation and to simplify and shorten the control design process as well.

$$
\begin{aligned}
& x=A(d) \cdot x+B \cdot V_{g} \\
& A=\begin{array}{ccccccc}
0 & 0 & 0 & 0 & \frac{-(1-d)}{C p} & \frac{-n 2}{n 1} \cdot \frac{1-d}{C p} & \frac{-1}{C p} \\
0 & \frac{-1}{R d \cdot C 2} & 0 & 0 & 0 & \frac{1}{C 2} & 0 \\
0 & 0 & \frac{-1}{R o \cdot C o} & 0 & 0 & 0 & \frac{1}{C o} \\
0 & 0 & 0 & 0 & 0 & \frac{1}{C 1} & 0 \\
\frac{1-d}{L 1} & 0 & 0 & 0 & 0 & 0 & 0 \\
\frac{n 2}{n 1} \cdot \frac{1-d}{L 2} & \frac{-1}{L 2} & 0 & \frac{-1}{L 2} & 0 & 0 & 0 \\
\frac{1}{L 3} & 0 & \frac{-1}{L 3} & 0 & 0 & 0 & 0
\end{array} \\
& \begin{array}{cr}
0 & V_{C 4} \\
0 & V_{C 2} \\
0 & V_{C 5} \\
0 & x=V_{C 1} \\
L 1 & i_{L_{1 A}} \\
\frac{1-\frac{n 2}{n 1}}{L 2} & i_{L 2} \\
0 & i_{L 3}
\end{array}
\end{aligned}
$$

Figure 5. State-space matrices of the Boost Topology with Ripple Cancellation Network.

Applying the decoupling concept to the circuit of Figure 1, $\mathrm{v}_{\mathrm{C} 4}, \mathrm{v}_{\mathrm{C} 5}$ and $\mathrm{i}_{\mathrm{L} 1 \mathrm{~A}}$ are considered slow variables while $\mathrm{v}_{\mathrm{C} 2}, \mathrm{v}_{\mathrm{C} 3}$, $i_{L 2}$ and $i_{L 3}$ are considered fast variables. Fast variables have been expressed as a function of the slow ones and the duty cycle. Solving the resultant system of equations an equivalent second order system has been obtained.

It can be seen that a second order system is presented although three slow variables have been identified. This simplification is possible if capacitances $\mathrm{C}_{4}$ and $\mathrm{C}_{5}$ are enough high and, as a result, the voltage on both capacitors can be considered to be the same. So, finally, a second order equivalent system is obtained (ecuations (1) and (2)).

An interesting property of this analysis is that the simplified model corresponds to an equivalent conventional boost converter, whose equivalent inductance is the inductance $\mathrm{L}_{1 \mathrm{~A}}$ and the equivalent capacitance is the parallel of the capacitances $\mathrm{C}_{4}$ and $\mathrm{C}_{5}$. 


$$
\begin{gathered}
\left(C_{4}+C_{5}\right) \cdot \frac{d V_{O}}{d t}=(1-d) \cdot i_{L_{1 A}}-\frac{V_{O}}{R} \\
L_{1 A} \cdot \frac{d i_{L_{1 A}}}{d t}=(1-d) \cdot V_{C_{5}}+V_{g}
\end{gathered}
$$

The main conclusion of this analysis is that the RHP zero is not cancelled for any design or operating condition, as in the conventional boost converter.

Figure 6 shows the accurate correspondence between the averaged model and the simplified transfer function in the control design frequency range, that is, until RHP zero's frequency, because the bandwidth of a converter with non minimum phase characteristics is limited approximately to one third of this frequency [9].
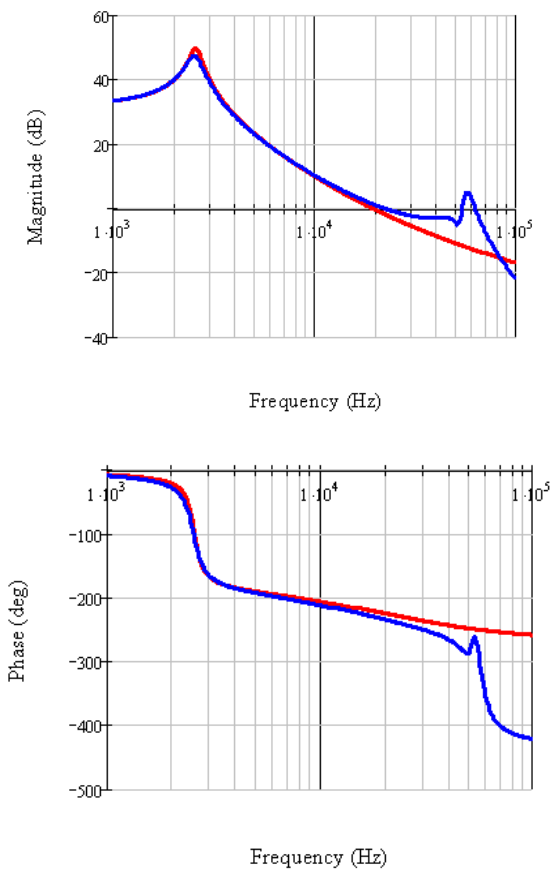

Figure 6. Bode plots comparison between the averaged model and the simplified transfer function (Vout/d).

\section{COMPARISON BETWEEN THE BOOST CONVERTER WITH RIPPLE CANCELLATION NETWORK AND THE CONVENTIONAL BOOST CONVERTER}

The dynamic analysis has shown that both topologies, conventional boost and boost with ripple cancellation, have the same dynamic behaviour in the frequency range useful for the control stage design. So it is of interest a comparison between both topologies in terms of weigh and losses.

In order to make a proper comparison, both designs should comply the following conditions:

- 500W output power

- Input voltage from $40 \mathrm{~V}$ to $96 \mathrm{~V}$

- Output voltage of $100 \mathrm{~V}$

- Maximum input and output current ripple of $20 \%$, chosen for a particular space application
- Output voltage ripple of $1 \%$ of its nominal value

- Floating capacitors voltage ripple of $5 \%$ of its nominal value

- Switching frequency of $150 \mathrm{kHz}$

- The magnetics components have been designed using Magnetics MPP toroidal cores, which have a density of $8.7 \mathrm{gr} / \mathrm{cm}^{3}$.

- The capacitors used are self-healing, necessary for a space application, chosen as a function of the capacitance and rms value.

The comparison shows that the weight of the magnetic components and capacitors is $117 \mathrm{gr}$ for the boost with ripple cancellation and 208gr for the conventional boost converter. In both cases the same input capacitor has been considered, despite this capacitor could have lower capacitance in the boost converter with ripple cancellation.

Although the developed losses comparison shows that both topologies have similar values, the boost converter with ripple cancellation is slightly better than the conventional boost, in terms of MOSFET and magnetic component losses.

Summaries of both designs are shown in tables I and II.

TABLE I

SUMMARY OF WEIGHT AND LOSSES FOR THE CONVENTIONAL BOOST CONVERTER

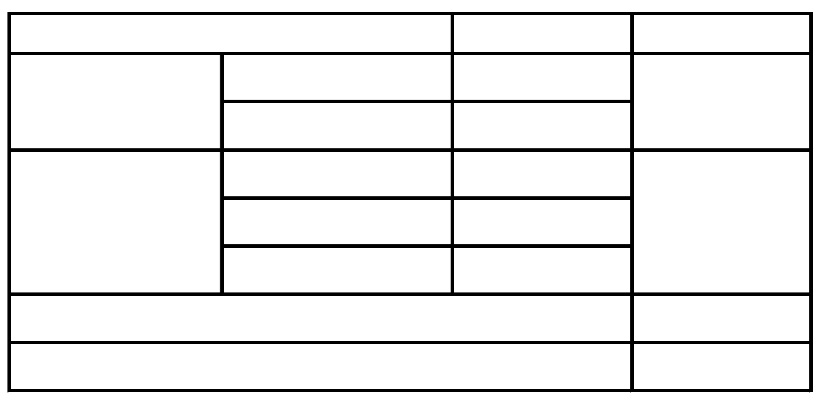

TABLE II

SUMMARY OF WEIGHT AND LOSSES FOR THE BOOST CONVERTER WITH RIPPLE CANCELLATION

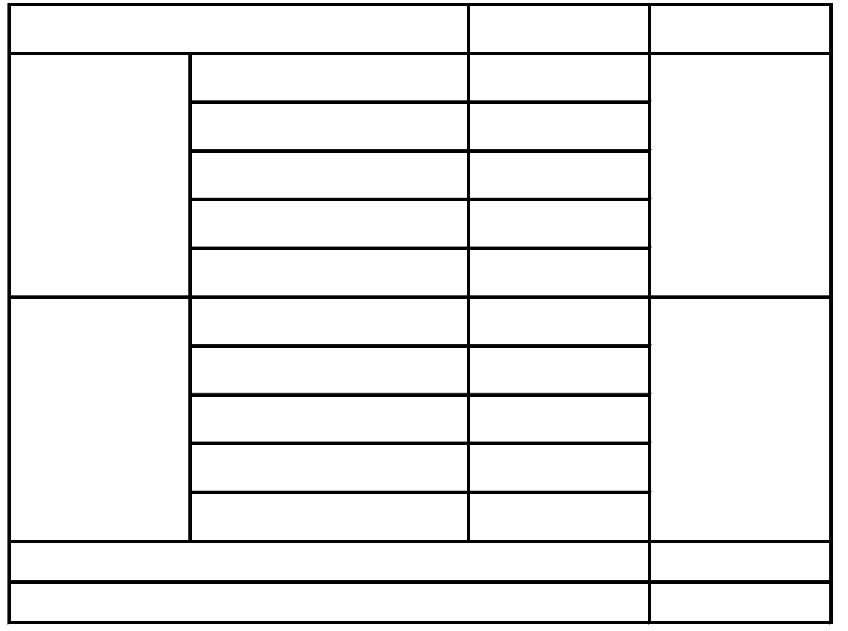

The number of switches and their voltage stress is the same on both topologies so the ripple cancellation topology, despite 
the higher number of components, is a better design option for these specifications, regarding weight and losses. Although $\mathrm{L}_{3}$ is small, it could be substituted by the leakage inductance of main magnetic component [10], reducing the number of magnetic components and the cost of the converter.

An estimation of the current ripple in the input and in the output of the topology can be obtained applying the ripple theorem presented in [11]. This theorem, applied to the presented averaged model, simplifies the ripple cancelation calculations, saves simulation time and allows a comparison between different designs in terms of ripple efficiency. Regarding the specifications a 2 A pk-pk ripple is obtained for inductor of the conventional boost topology, for an input voltage of $50 \mathrm{~V}(\mathrm{~d}=0.5)$.

Applying the ripple theorem proposed in [11], a ripple of 95 $\mathrm{mA}$ pk-pk has been obtained for the input current $\left(i_{\text {in }}\right.$ on Figure 1) of the ripple cancellation boost converter, for the same input voltage.

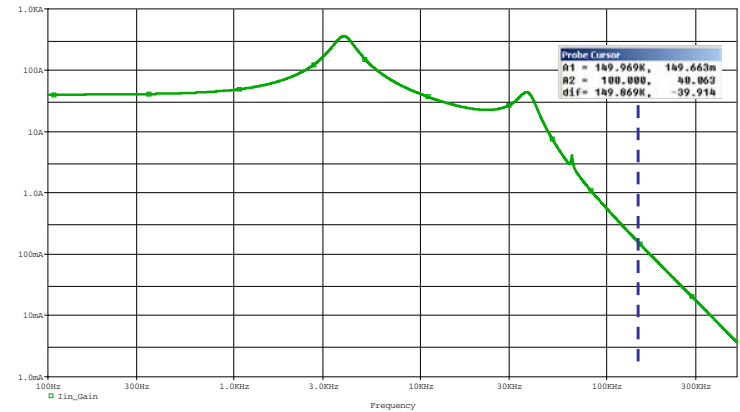

(a)

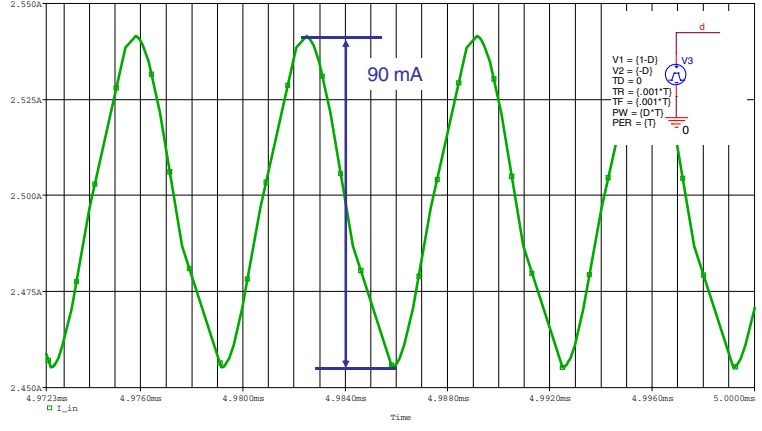

(b)

Figure 7. Magnitude bode plot of the ripple cancelation boost converter (a). Input current and ac component of the steady-state of the switching signal (b).

Figure 7.a shows the magnitude bode plot of this input current and the gain at the switching frequency, used to obtain the current ripple given by the ripple theorem.

$$
\Delta i_{p k-p k}=0.149 \cdot \frac{\sin (\pi \cdot 0.5)}{\pi \cdot 0.5}=95 m A_{p k-p k}
$$

A transient simulation (figure 7.b) applying the ac component of the steady-state of the switching signal to the averaged model has been performed, in order to check the theoretical calculations of the input current ripple.

\section{EXPERIMENTAL RESULTS}

A $500 \mathrm{~W}$ prototype has been developed (Figure 8) according to the specifications shown in the previous section. The efficiency of the converter is between $92 \%-96.5 \%$.

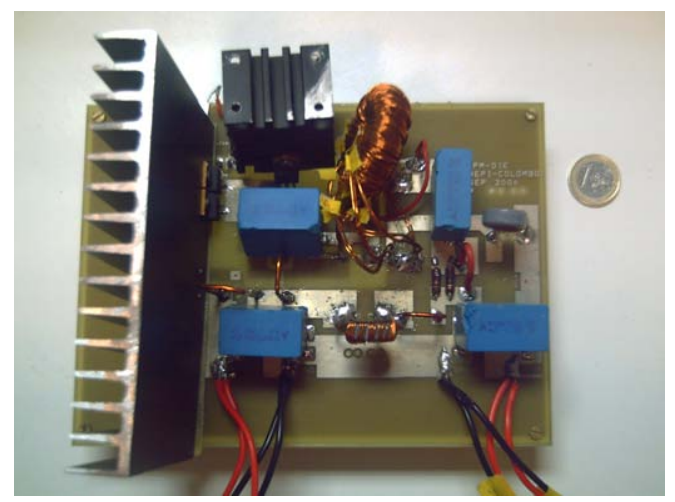

Figure 8. Photography of the Boost with Ripple Cancellation Network.

In order to validate the current ripple cancellation for any working condition, several tests in both conduction modes have been carried out. On Figure 9, the current $i_{1}$ (Figure 1) is the cancellation network current, $i_{2}$ is the current before the switching network and $i_{\text {in }}$ is the addition of both, the current supplied at the input. It can be seen that the cancellation is achieved for both conduction modes.

A critical parameter for input current ripple cancellation, the inductor L2, has been designed with an inductance of $7.8 \mathrm{uH}$ (about 20\% lower than the theoretical value) in order to evaluate current ripple cancellation for a not optimized design. Although total current cancellation is not achieved, it can be observed that input current ripple is very small.

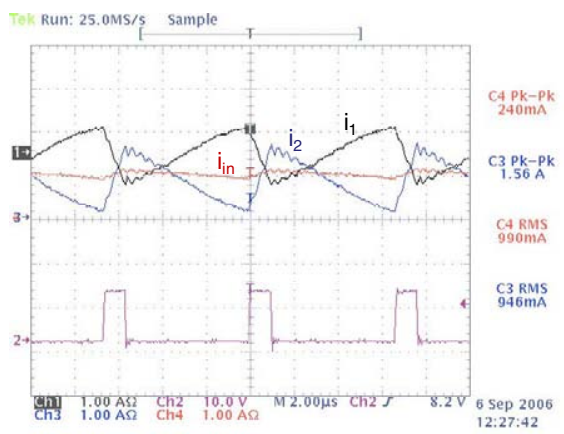

(a)

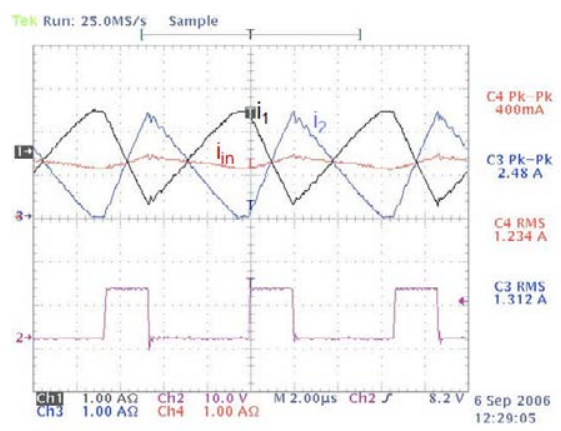

(b)

Figure 9. Measured Waveforms for CCM (a) and DCM operation(b). 
Also the output current has been measured and the ripple cancellation has been validated (Figure 10).

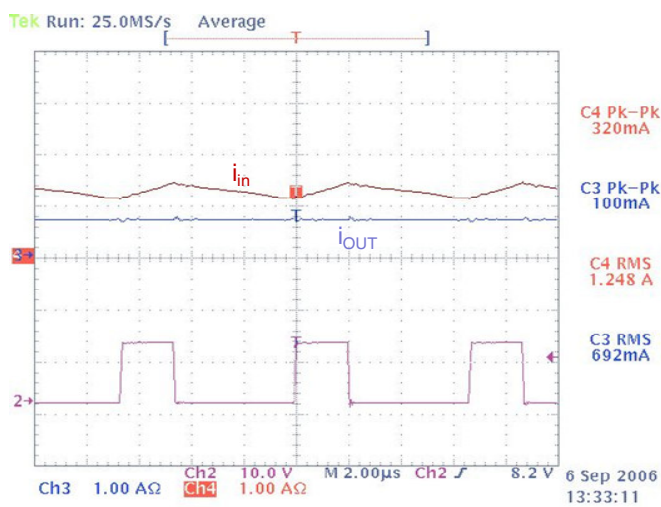

Figure 10. Input and output current of the Boost with Ripple Cancellation Network.

As it was mentioned in section II, where the averaged model was presented, a comparison between the simulated bode plot and the measured one has been realized. It can be seen on figure 11 that both bode plots fit in the frequency range.
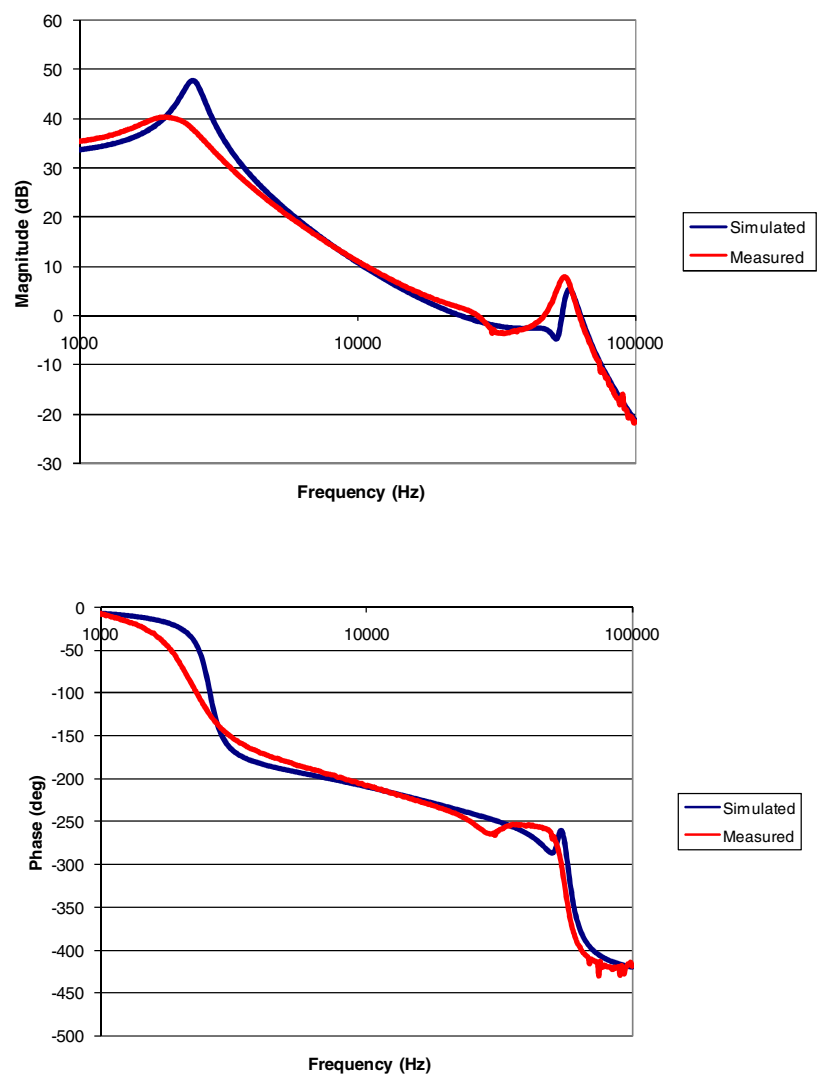

Figure 11. Measured and simulated Bode plot of the boost topology with ripple cancellation.

\section{CONCLUSIONS}

A boost topology with ripple cancellation network has been analyzed. This topology reduces input and output current ripple, by means of a ripple cancellation network and the magnetic component $\mathrm{L}_{3}$ respectively. The averaged model has been obtained and validated by a comparison with the measured bode plot. The theoretical transfer function control to output voltage transfer function has been obtained. Also a second order simplification has been obtained in order to simplify the control stage design and to check that the RHP zero appears for all operating conditions, as in the conventional boost converter. Using the averaged model, the input current ripple of the boost with ripple cancellation has been estimated and compared with the conventional boost.

A comparison between this topology and the conventional boost in terms of weight and efficiency has been performed. This comparison shows that the ripple cancellation boost converter takes advantage from the point of view of weight (118 gr, $57 \%$ of the weight of the conventional boost) and losses, especially for aerospace applications. A prototype has been developed to validate the current cancellation for both conduction modes, including waveforms.

\section{REFERENCES}

[1] R. Martinelli, C. Ashley, "Coupled Inductor Boost Converter with Input and Output Ripple Cancellation", IEEE APEC 1991, pp. 567-572.

[2] E. Sanchis-Kilders, J.B. Ejea, A. Ferreres, E. Maset, V. Esteve, J. Jordán, J. Calvente, A. Garrigós, "Bidirectional Coupled Inductors Step-up Converter for Battery Discharging-Charging”. IEEE PESC '05, pp. 64-68.

[3] P.Rueda, S.Ghani, P.Perol, "A New Energy Transfer Principle to achieve a Minimum Phase \& Continuous Current Boost Converter". IEEE PESC 2004 p.2232-2236, vol. 3.

[4] J.A. Oliver, J.A. Cobos, J. Uceda, M. Rascón and C. Quiñones, "Systematic approach for developing large-signal averaged models of multioutput PWM converters", IEEE PESC 2000, pp. 696-701, vol. 2.

[5] B. Bryant and M. K. Kazimierczuk, "Voltage-Loop Power-Stage Transfer Functions with MOSFET delay for Boost PWM Converter Operating in CCM", IEEE Trans. on Ind. Electron., vol. 54, No. 1, pp. 347-353, Feb. 2007.

[6] R.D. Middlebrook, S. Cuk, "A General Unified Approach to Modelling Switching-Converter Power Stages”, IEEE PESC'76, pp. 18-34.

[7] J. Sun, H. Grotstollen. "Averaged Modelling of Switching Power Converters: Reformulation and Theoreticall basis" IEEE PESC'92, pp.1165-1172 vol.2.

[8] Jian Sun; Grotstollen, H. "Symbolic Analysis Methods for Averaged Modeling of Switching Power Converters" IEEE Trans. on Power Electronics, vol. 12, No 3, pp. 537-546, May 1997.

[9] R. Ridley, "Switching Power Magazine", January 2001 p.22-25.

[10] Michael J. Schutten, Robert L. Steigerwald, Juan A.Sabaté, "Ripple Current Cancellation Circuit" IEEE APEC 2003, pp. 464 - 470 vol.1.

[11] V. Vorperian, "A ripple theorem for PWM DC-to-DC converters operating in continuous conduction mode", IEEE PESC 2004, pp. 28-35 vol.1. 